\title{
OPTIMIZATION OF MACHINING PARAMETERS ON TOOL TIP TEMPERATURE BY USING VEGETABLE OIL ON EN8 MATERIAL
}

\author{
Vishav Kainth ${ }^{1}$, Rickramjeet Singh ${ }^{2}$, \\ ${ }^{1}$ Lecturer, Dept. of Mechanical Engineering, GGS College Of Modern technology, Chandigarh, India \\ ${ }^{2}$ Workshop Superintendent, Dept. of Mechanical Engineering, Gian jyoti College of Institutions, Banur, India \\ Kainth.vishav@gmail.com,rickramjeet01@gmail.com,
}

\begin{abstract}
In this research the experiments were performed by using vegetable oil to know the effect of different machining parameters on tool tip temperature. The quality of work piece material is main contributing factor in these days which may be influence by heat generated at the tool tip temperature. For this experimental work different machining parameters were used depth of cut, speed and feed rate, and work piece on the tool tip temperature during a machining ofEN8 material. To study the influence of each parameter on tool tip temperature total 9 experiments were performed in order to find the minimum tool tip temperature. The experiments were performed by varying one parameter while, the keep two parameter were kept constant. So the influence of tool tip temperature on varying machining parameters is studied in this research work. The main objective of this study is to investigate the effect of cutting parameters and to find out optimal conditions of spindle speed, feed, and depth of cut and work piece material for achieving minimum temperature and to increase the quality of work peice material by reducing the temperature using vegetable. In this experiment tool tip temperature measurement instrument is used to find the optimum parametric conditions like spindle speed, feed and depth of cut on EN-8 material. The analysis reveals that spindle speed has major effect on tool tip temperature while using Soya oil as lubricant.
\end{abstract}

Key Words: Tool tip temperature, spindle speed, feed rate and Depth of cut.

\section{INTRODUCTION}

In the today scenario the main purpose of machining is to improve quality of the component and to enhance production related problems. The quality of the component is greatly impacted by parameters like material removal rate, tool life, wear rate and tool tip temperature at work piece which decide the productivity and economic conditions by machining using different vegetable based cutting oils and fluids. During machining of work piece at tool work piece interface the power is converted into heat and high temperature is measured at tool tip. But the amount of heat generated at tool tip is varying with the type of material or oil being used during machining. Therefore for this purpose to know how much minimum temperature is being obtained at tool tip vegetable based cutting fluid (soya oil) is used as lubricant during cutting. The enhancement of use of industrial lubricants effect the worker health related problems which effect the production. So to eliminate the use of industrial lubricants we use vegetable based cutting oils which don't have any effect on worker health and also it reduces the friction. Moreover the vegetable based cutting oils are free from pollution related problems and these oils don't impact on worker health during machining. The primary objective of industrial lubricant is to reduce friction and to reduce heat at tool tip temperature to obtain minimum temperature. So for these vegetable based cutting oils serve the purpose. The objective of this study is to obtain minimum temperature by using soya oil as lubricant to find out best optimal parameters of spindle speed, feed and depth of cut to achieve minimum temperature.

\section{LITERATURE REVIEW}

Sushil D. Ghodam [5] discuss the effect of temperature distribution on tool life and on the chip-tool interface. In this project work the temperature generates on rake face of tool tip chip temperature has measured by using tool work thermocouple technique. He also study that temperature at shear face is high. The tool work thermocouple technique is best method for measuring tool tip temperature at tool tip interface during cutting operation due to it is easy to set up during machining. S.B.Chawale et al [2], investigate the effect of machining parameters on temperature at cutter work piece interface by using different machining parameters like spindle speed, depth of cut and feed in milling. For this study experiments were performed on milling machine to know the effect of each factor. The data shows that speed is most promising factor and feed is third factor having less percentage contribution than other two factors. Gheorghe ceau et al [3], conducted the experiments to measure the temperature at cutting edge by using natural thermocouple technique. In this paper the researchers reveal different temperature measuring techniques i.e. infrared camera, optical pyrometer and natural thermocouple. $\mathbf{K}$. Subramanyam et al [6], evaluate the effect of CBN cubic boron nitride and ceramic tool at tool tip temperature .The study reveal that minimum tool tip temperature was obtained by using CBN tool than ceramic tool. S.H. Rathod and Mohd. Razik [4] worked to find tool tip temperature by using high speed machining at High Speed Steel and of a Carbide Tip Tool .The experiments performed were show that speed is most promising parameter that effect tool tip 
interface temperature and feed is $2^{\text {nd }}$ and depth of cut is third parameter having least significant effect to obtain minimum temperature. The study also shows that change in speed has maximum effect on increasing the temperature. Patrick Adebisi Olusegun Adegbuyi[8] investigated the effect of cutting fluids used for machining .The reason for being use of cutting fluids in cutting are many i.e. to improve tool life, to reduce friction, and to reduce tool work piece interface temperature and to improve surface finish and increased production can be achieved by the use of cutting fluids. In this work soluble oil, water and palm kernel oil were used as coolants in turning operations. HaciSaglam et al [7] evaluated the effect of cutting speed on main cutting force and tool tip temperature. In this study, the effects of rake angle and cutting speed on cutting force and the temperature generated on the tool tip is investigated. During the tests, the depth of cut and feed rate were kept constant. The orthogonal arrays as L16 were used with a total of 16 tests. Finally, it was found that rake angle was effective .While cutting speed was effective on the tool tip temperature.

Asmaa A. Kawi [1] studied the temperature behaviour of some alloys by using Finite element and thermocouple technique. The results obtained shows that some alloys have increasing temperature by increasing feed and also Finite element analysis is best method to analyse the cutting temperature. Hardeep Singh et al [10] investigated the temperature behaviour on EN9 material by using infrared thermometer technique. The research show in this paper reveal that Feed is most promising parameter in controlling temperature on EN9 material without using any lubricant in machining.A.V dhote et al[9] studied the effect of machining parameters on tool tip temperature without using any oil or cutting fluid. The experiments are conducted by using Taguchi L9 orthogonal array and in the end by using L9 orthogonal array optimized cutting parameters were also found and rake angle and force is also being measured which is applied during machining. In this work tool angel were also being measured by using profile projector.

\section{EXPERIMENTAL SETUP}

For the present project work to measure the tool tip temperature we used Tool tip temperature measurement instrument. There are different temperature measuring instruments which are used to measure the temperature of tool tip like infrared thermometer, optical pyrometer, and thermocouple technique. For doing the experimental run $250 \mathrm{~mm}$ Rod is taken and rod is divided into 10 equal portions for conducting different runs at different conditions .Tool tip temperature measurement instrument used for measuring temperature. At every Rpm during machining on lathe We take three readings of temperature and after that an average of three readings is taken as final measured temperature at specified region of that part. After completing the experiments we will know how temperature is varying with the increase of rpm, feed or depth of cut.

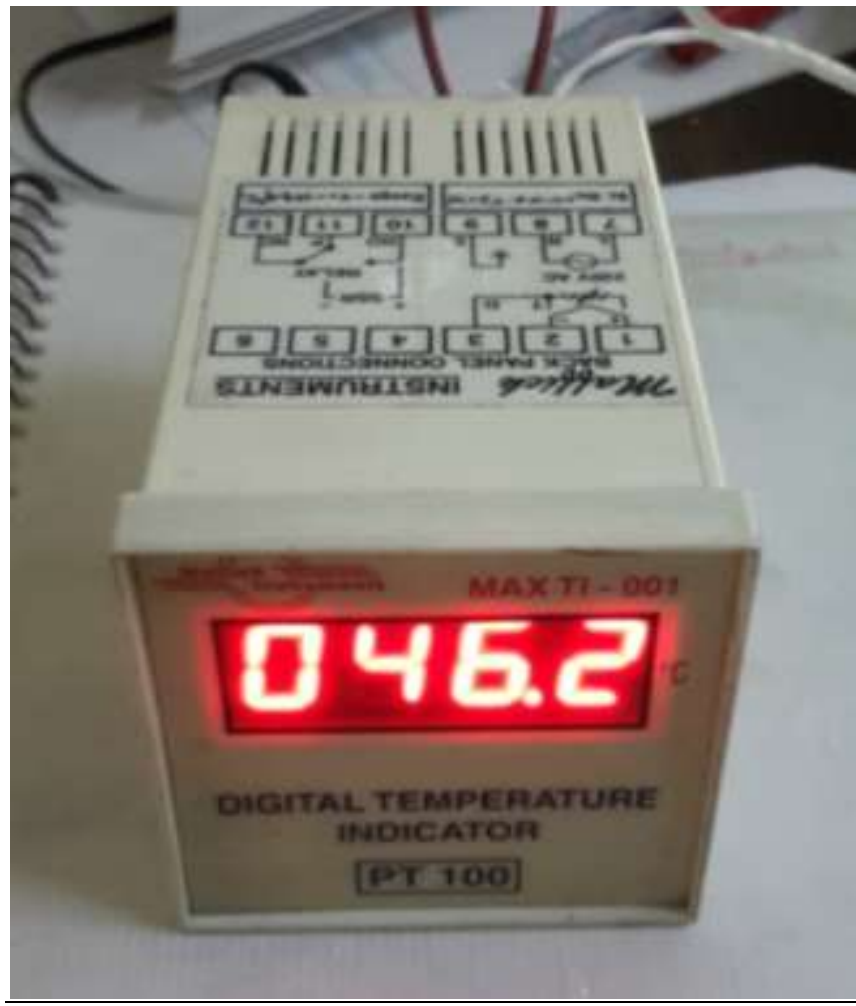

Fig: - 1 Digital temperature indicator

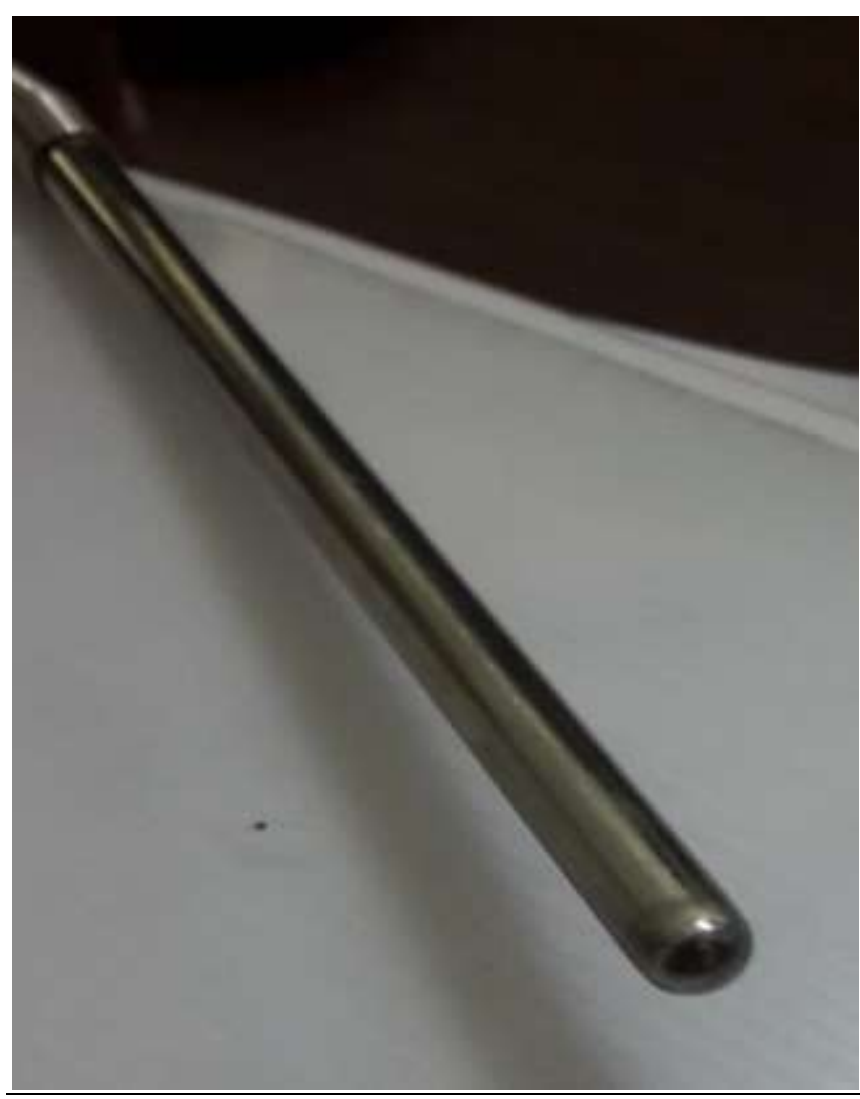

Fig: - 2 Tip for Temperature measurement set 


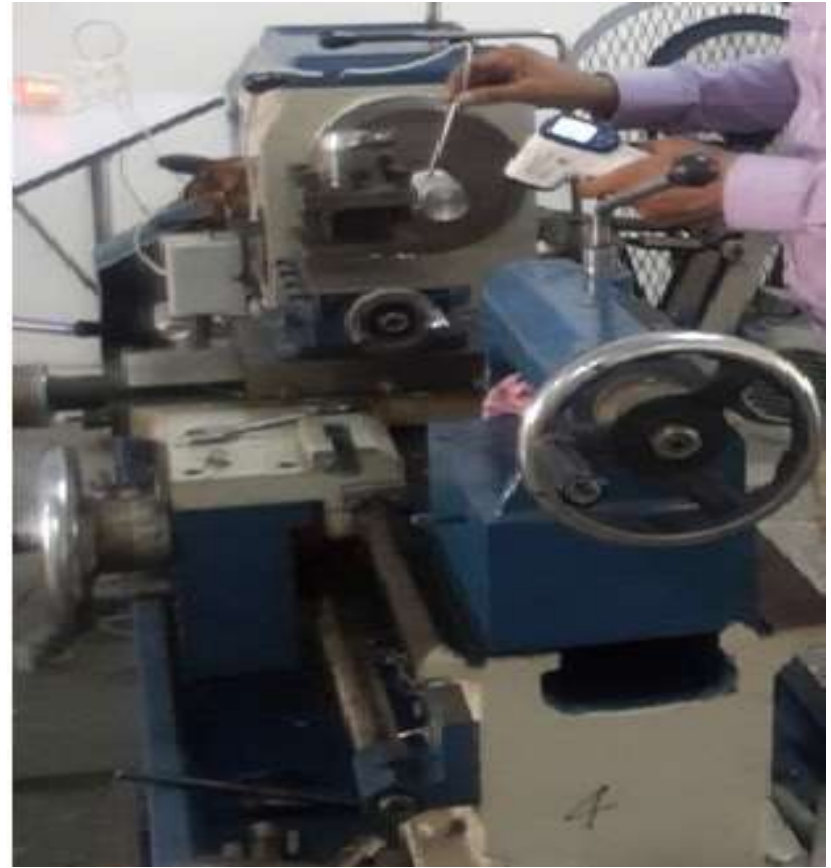

Fig: - 3 Tool tip Temperature measurement set up

\subsection{Vegetable Based Cutting Fluid}

In these days vegetable based cutting fluids are in research in place of industrial based cutting fluids and oils. The purpose which industrial oil serves same purpose in research of study these days by using vegetable based oils i.e to reduce friction and improve tool life are main consideration of today scenario are in research by many researchers. The reason for use of vegetable based cutting oils is it is environment friendly and moreover it does not pollute the environment where machining is going to be done.

\subsection{Work piece Materials and Cutting Tools}

The work piece material used in the present work is EN8 because of its application in industry.

\subsection{Experimental Design}

In this study, cutting speed, feed rate, depth of cut And soya oil used as cutting fluid were considered as constant Parameter. An L9 (3) Taguchi orthogonal array was Used as the experimental design. The parameters Investigated and the levels were indicated in Table 2.

Table:-1 Machining parameters and there levels

\begin{tabular}{|l|l|l|l|}
\hline LEVEL & $\begin{array}{l}\text { Spindle speed } \\
\text { (RPM) }\end{array}$ & $\begin{array}{l}\text { feed } \\
(\mathrm{mm} / \mathrm{rev})\end{array}$ & $\begin{array}{l}\text { Depth of } \\
\operatorname{cut}(\mathrm{d})(\mathrm{mm})\end{array}$ \\
\hline 1 & 180 & 0.05 & 1 \\
\hline 2 & 275 & 0.1 & 1.5 \\
\hline 3 & 465 & 0.2 & 2 \\
\hline
\end{tabular}

\subsection{Tool Tip temperature Measurement}

The temperature of cutting tool is measured by using tool tip temperature measuring system. To determine the cutting tool temperature during the turning operation using embedded thermocouple technique.

\section{SPECIFICATION:}

1. Temperature range:0-1200 c

2. Sensor type: $\mathrm{K}$ chromel Alumel

3. 230 volts input $50 \mathrm{~Hz}$

4. Accuracy: $1 \mathrm{c}$

5. Thermocouple-Fe/K(K-type)

6. Indicator:3 $1 \frac{1}{2}$ digit display

7. Panel:metallic duly powder coated

Table - 2: Experimentation for Vegetable oil (SOYA OIL), as lubricant to measure Tool tip Temperature.

\begin{tabular}{|l|l|l|l|l|}
\hline $\begin{array}{l}\text { S. } \\
\text { NO }\end{array}$ & $\begin{array}{l}\text { Spindle } \\
\text { speed } \\
(\mathrm{RPM})\end{array}$ & feed & $\begin{array}{l}\text { Depth of } \\
\text { cut(d) } \\
(\mathrm{mm})\end{array}$ & $\begin{array}{l}\text { Temperature } \\
\text { Measured } \\
\text { (Deg celcius })\end{array}$ \\
\hline 1 & 180 & 0.05 & 1 & 29 \\
\hline 2 & 275 & 0.05 & 1.5 & 32 \\
\hline 3 & 465 & 0.05 & 2 & 36 \\
\hline 4 & 180 & 0.1 & 1.5 & 31 \\
\hline 5 & 275 & 0.1 & 2 & 38 \\
\hline 6 & 465 & 0.1 & 1 & 43 \\
\hline 7 & 180 & 0.2 & 2 & 41 \\
\hline 8 & 275 & 0.2 & 1 & 46 \\
\hline 9 & 465 & 0.2 & 1.5 & 52 \\
\hline
\end{tabular}

\section{EXPERIMENTAL RESULTS AND DISCUSSION}

In order to see the effect of Machining parameters on Tool Tip Temperature, experiments were conducted using L9 OA.

Table 3: Response Table for Signal to Noise Ratio

\begin{tabular}{|l|l|l|l|}
\hline Level & $\begin{array}{l}\text { Spindle } \\
\text { Speed }(\mathrm{rpm})\end{array}$ & $\begin{array}{l}\text { Feed } \\
(\mathrm{mm} / \mathrm{rev})\end{array}$ & $\begin{array}{l}\text { Depth of Cut } \\
(\mathrm{mm})\end{array}$ \\
\hline 1 & -30.16 & -30.44 & -31.72 \\
\hline 2 & -31.36 & -31.65 & -31.42 \\
\hline 3 & -33.28 & -32.71 & -31.66 \\
\hline Delta & 3.12 & 2.26 & 0.31 \\
\hline Rank & 1 & 2 & 3 \\
\hline
\end{tabular}

Table: 4 Main Effects Plot for SN ratios

\begin{tabular}{|l|l|l|l|}
\hline Level & $\begin{array}{l}\text { Spindle } \\
\text { Speed }(\mathrm{rpm})\end{array}$ & $\begin{array}{l}\text { Feed } \\
(\mathrm{mm} / \mathrm{rev})\end{array}$ & $\begin{array}{l}\text { Depth of Cut } \\
(\mathrm{mm})\end{array}$ \\
\hline 1 & 32.33 & 33.67 & 39.33 \\
\hline 2 & 37.33 & 38.67 & 38.33 \\
\hline 3 & 46.33 & 43.67 & 38.33 \\
\hline Delta & 14.00 & 10.00 & 1.00 \\
\hline Rank & 1 & 2 & 3 \\
\hline
\end{tabular}

\section{Analysis of Variance}

Table 5: Response Table for Analysis of Variance

\begin{tabular}{|l|l|l|l|l|l|}
\hline Source & DF & $\begin{array}{l}\text { Adj } \\
\text { SS }\end{array}$ & $\begin{array}{l}\text { Adj } \\
\text { MS }\end{array}$ & FValue & PValue \\
\hline Spindle speed (rpm) & 2 & 302.0 & 151.0 & 5.734 & 0.041 \\
\hline Feed (mm/rev) & 2 & 150.0 & 75.00 & 1.452 & 0.306 \\
\hline Depth of Cut (mm) & 2 & 2.00 & 1.00 & 0.013 & 0.987 \\
\hline Error & 2 & & & & \\
\hline Total & 8 & & & & \\
\hline
\end{tabular}




\section{CONFIRMATION TEST}

Table: 6 Parameters used in the confirmation.

\begin{tabular}{|l|l|l|l|}
\hline S.NO & $\begin{array}{l}\text { Spindle speed } \\
(\mathrm{rpm})\end{array}$ & $\begin{array}{l}\text { feed } \\
(\mathrm{mm} / \mathrm{rev})\end{array}$ & $\begin{array}{l}\text { Depth of cut } \\
(\mathrm{mm})\end{array}$ \\
\hline 1 & 180 & 0.05 & 1 \\
\hline 2 & 275 & 0.05 & 1.5 \\
\hline 3 & 465 & 0.05 & 2 \\
\hline 4 & 180 & 0.1 & 1.5 \\
\hline 5 & 275 & 0.1 & 2 \\
\hline 6 & 465 & 0.1 & 1 \\
\hline 7 & 180 & 0.2 & 2 \\
\hline 8 & 275 & 0.2 & 1 \\
\hline 9 & 465 & 0.2 & 1.5 \\
\hline
\end{tabular}

Table: 7 Confirmation test results

\begin{tabular}{|l|l|l|}
\hline S.NO & $\begin{array}{l}\text { Predicted tool Tip } \\
\text { temperature }\end{array}$ & $\begin{array}{l}\text { Experimental tool } \\
\text { tip temperature }\end{array}$ \\
\hline 1 & 27.2 & 29 \\
\hline 2 & 28.8 & 32 \\
\hline 3 & 31.5 & 36 \\
\hline 4 & 29.2 & 31 \\
\hline 5 & 34.8 & 38 \\
\hline 6 & 36.3 & 43 \\
\hline 7 & 35.5 & 41 \\
\hline 8 & 38.2 & 46 \\
\hline 9 & 43.9 & 52 \\
\hline
\end{tabular}

The above table shows experimental tool tip temperature and predicted tool temperature values are closely related.

\section{CONCLUSION}

After conducting experimental work and analysis the result reveal the optimized parameter for machining by using Soya oil on EN8 material. The results obtained from the ANOVA shows that spindle speed is the highest significant parameter followed by depth of cut and feed rate. Therefore it shows that speed is most important parameter to reduce the tool tip temperature than other remaining two parameters. The optimized parameter setting is also found by using taguchi L9 orthogonal array. The study also shows that minimum temperature be can obtained by using soya oil as lubricant. The parameter setting found from optimization is confirmed by using confirmation results that is it is compared with experimental and predicted results to found that optimized setting found are correct after conducting confirmation results.

\section{REFERENCES}

[1]. X. L. Liu, D. H. Wen, Z. J. Li, L. Xiao, F. G. Yan, 2002, "Cutting temperature and tool wear of hard turning hardened bearing steel", Journal of Materials Processing Technology 129, pp 200-206.

[2]. L. B. Abhang, M. Hameedullah, 2012, "Chip-Tool interface temperature prediction model for turning process", International journal of Engineering science and technology 2, pp. 382-393.
[3]. Pradip Mujumdar, R. Jayaramachandran, S. Ganesan, 2005, "Finite element analysis of temperature rise in metal cutting processes", Applied Thermal Engineering 25, pp. 2152-2168

[4]. Dr.S.S.Chaudhari, S.S. Khedkar and N.B. Borkar. "Optimization of process parameters using Taguchi approach with minimum quantity lubrication for turning", International Journal of Engineering Research, Vol.1 (4), 1268-1273.

[5]. H. Yang and Y.S. Tarng (1998), Design optimization of cutting parameters for turning operations based on the Taguchi method', Journal Of Materials Processing Technology, Vol. 84, pp. 122-129.

[6]. Sullivan.D.O, Cotterall. M., "Temperature measurement in single point turning" Journal of Material Processing Technology 118: 301 - 308, 2001.

[7] S.A. Lawal, I.A. Choudary, Y. Nukman, Application of vegetable oil-based metal working fluids in machining ferrous metals - A review. International Journal Of Machine Tools \& Manufacture 52(2012) pp.1-12

[8] Patrick Adebisi Olusegun Adegbuyi,“ Optimization of CNC end milling process parameters using PCA-based Taguchi method ",International Journal of Engineering, Science and Technology Vol. 2, No. 1, 2010, pp. 92-102.

[9]. Liu. X.L.; Wen.D.H; Li. Z.J; Xiao.L; Yan.F.G., “Cutting temperature and tool wear of hard turning ofhardened bearing steel", Journal Of Material ProcessingTechnology 129: 200 - 206, 2002.

[10] .Hari Singh, in: International Multi Conference of Engineers and Computer Scientists, Vol. II, IMECS, Hong Kong (2008) 19-21.

[11]. S. Thamizhmanii, S. Saparudin and S. Hasan (2007), Analyses of surface roughness by turning process using Taguchi method, Journal of Achievements in Materials and Manufacturing Engineering,Vol. 20, pp. 503-506

[12]. Tugrul Özel and Taylan Altan , "Modeling of high speed machining processes for predicting tool forces, stresses and temperatures using fem simulations," Proceedings of the CIRP International Workshop on Modeling of Machining Operations Atlanta, Georgia, USA May 19, 1998. 